\title{
Post-aerobic digestion of waste sludge: performance analysis and modelling of nitrogen fate under alternating aeration
}

\author{
M. C. Tomei $^{1} \cdot$ N. A. Carozza $^{1} \cdot$ D. Mosca Angelucci ${ }^{1}$
}

Received: 22 October 2014/Revised: 26 February 2015/ Accepted: 29 June 2015/Published online: 17 July 2015

(C) Islamic Azad University (IAU) 2015

\begin{abstract}
Combined anaerobic-aerobic sludge digestion has been demonstrated as a valid technological solution to improve the sludge stabilization process, in terms of solid reduction and sludge dewaterability properties. In this study, we investigated the fate of all nitrogen species (ammonia, nitrites, nitrates) in the sequential digestion process when the post-aerobic step is operated with intermittent aeration. Nitrogen course has been followed in the two digesters operated in semi-continuous mode and in batch nitrification-denitrification kinetic tests. Two-stage digestion was applied to real waste activated sludge. High volatile solid removal efficiencies (47 and $26 \%$ in the anaerobic and aerobic phases, respectively) confirmed the potential of this technology. Moreover, the post-aerobic stage allowed to successfully achieving nitrogen removal through the simultaneous nitrification-denitrification process. Nitrification and denitrification efficiencies were 95 and $70 \%$, respectively. Batch tests for nitrification and denitrification were also carried out to investigate the process kinetics. A process model has been formulated and calibrated with a first set of experimental kinetic data. Evaluated kinetic parameters were employed in the validation phase successfully performed (correlation coefficients $R^{2}>0.98$ ) with different series of experimental data.
\end{abstract}

Keywords Alternate aeration - Nitrificationdenitrification - Nitrogen removal · Process modelling . Sequential digestion

M. C. Tomei

tomei@irsa.cnr.it

1 Water Research Institute, C.N.R., Via Salaria km 29.300, Monterotondo Scalo, 00015 Rome, Italy

\section{Introduction}

Sequential anaerobic-aerobic digestion has been proposed as effective process able to improve the performance of the conventional single-stage anaerobic and aerobic sludge digestion, which are the most common stabilization methods in Europe (Kelessidis and Stasinakis 2012). The rationale of this technological solution derives from the availability in the sequential configuration of reaction environments suitable for the biodegradation of the different sludge fractions.

Several previous papers (Kumar et al. 2006; Parravicini et al. 2008; Tomei et al. 2011a) highlighted the advantages of a post-aerobic stage following the conventional anaerobic sludge digestion. Besides the increase in VS abatement efficiency and COD reduction (Tomei et al. 2011a), the improvement of sludge dewaterability characteristics is reported. Recent studies (Zupancic and Ros 2008; Tomei and Carozza 2014) investigated the possibility of achieving an ulterior beneficial effect: the nitrogen removal in the supernatant of the sludge digestion. This feature is of absolute relevance, not only for the sludge line, but also for the whole wastewater treatment plant (WWTP) because it could significantly reduce the nitrogen load recycled to the plant. This additional nitrogen load, generally considered negligible in plant design, could be, on the contrary, significant accounting up to $50 \%$ of the influent nitrogen load (Zupancic and Ros 2008); thus, the possibility of achieving a contemporary nitrogen removal during digestion is certainly of interest.

This alternative was investigated on mixed sludge, primary plus waste activated sludge (WAS), by different authors. Parravicini et al. (2008) with an optimization study performed on a full-scale plant demonstrated the possibility of achieving practically complete nitrification (98\% 
efficiency) and $45 \%$ nitrogen removal by intermittent aeration in the post-aerobic stabilization performed at $6 \mathrm{~d}$ of sludge retention time (SRT). Partial denitrification (51\% efficiency) was observed by Tomei et al. (2011a) working at SRT of 12 days in the aerobic stage and at a dissolved oxygen (DO) value of $3 \mathrm{mg} / \mathrm{L}$ lower than the limit required to ensure favourable conditions for nitrification (Zupancic and Ros 2008). Therefore, nitrogen removal in this case was presumably attributable to the effect of a simultaneous nitrification-denitrification process. A different solution in order to achieve nitrogen removal in the stabilization process has been proposed by Novak et al. (2011) with a three-stage sequential digestion anaerobic-aerobic-anaerobic plant layout in which the aerobic digested sludge is concentrated (by centrifugation) and recycled back to the anaerobic digester. The sludge was wasted either from the anaerobic or from the aerobic unit, and this choice significantly affected the nitrogen fate: TKN removal efficiency was $45 \%$ when the sludge was wasted from the anaerobic unit but increased to $70 \%$ if the wastage is done from the aerobic one.

Starting from the valuable results reported in the abovementioned studies, in this work we focused the attention on WAS assuming that the separate treatment of primary and secondary sludge could be a convenient alternative for high-potentiality WWTPs (Mininni et al. 2004). WAS is characterized by worse digestibility in comparison with mixed sludge, so a more effective digestion process has a relevant impact on the stabilization of this sludge fraction. Previous studies (Tomei et al. 2011b; Tomei and Carozza 2014) were mainly focused on the classical stabilization parameters and reported the superior performance in terms of VS and COD removal of sequential digestion of WAS in comparison with conventional mesophilic anaerobic digestion.

The objective of this study was to investigate the fate of all nitrogen species (ammonia, nitrites, nitrates) in the sequential digestion process when the post-aerobic stage is operated with intermittent aeration. Nitrogen course has been followed in the two digesters operated in semi-continuous mode and in batch nitrification-denitrification kinetic tests. Experimental data were utilized to formulate a model of the nitrogen removal process, which, to the best knowledge of the authors, is not available in the specialized literature for the sequential anaerobic-aerobic sludge digestion. The model was calibrated through the fitting of a first series of experimental data and then successfully validated with different series of data.

The research activity was carried out at the Water Research Institute of the Italian National Research Council (CNR) located in Rome (Italy) during the period January 2013-February 2014.

\section{Materials and methods}

\section{Sludge}

WAS originated from a municipal WWTP (located in Rome, Italy) has been utilized in the experiments. The plant is a conventional urban activated sludge system including pre-treatments, primary clarification and secondary treatment and serves about 700,000 P.E. Sludge was collected from the aeration basin, gravity thickened for 18-24 $\mathrm{h}$ and stored at $4{ }^{\circ} \mathrm{C}$ until used.

\section{Experimental apparatus and operation}

Two bench-scale glass reactors (7 L each) cylindrical shaped were used for the experiments. Mechanical stirrers fitted with helicoidal blades ensured mixing, and a thermostatic jacket connected to a control device maintained the process temperature. The reactors were operated in series: the anaerobic one at $T=37 \pm 0.5^{\circ} \mathrm{C}$ (mesophilic conditions), working volume $7 \mathrm{~L}$ and 15 days SRT, while the aerobic reactor was operated at $T=20 \pm 0.5{ }^{\circ} \mathrm{C}$, working volume $4.5 \mathrm{~L}$ and SRT 12 days. Both reactors were fed once per day: the anaerobic digester was fed with real WAS (provided by the full-scale plant), while the aerobic reactor was fed with the anaerobic digested sludge withdrawn from the first reactor. In both cases, the feeding is very fast (it can be considered almost instantaneous) and the reactors are mixed during the feed phase.

In the aerobic digester, air was supplied by a compressor at a flow rate suitable to maintain the DO at a set point value $\geq 3 \mathrm{mg} / \mathrm{L}$. Intermittent aeration (40-min on and 20-min off) was applied in order to achieve simultaneous nitrification-denitrification. The main objective of the postaerobic stabilization in the sequential digestion process is to ensure the completion of the aerobic biodegradation for the VS fractions not biodegradable under anaerobic conditions and efficient nitrification. Therefore, the distribution of the aerated and not aerated phases has been optimized to achieve efficient VS removal and high nitrification efficiencies. Alternate aeration performance was verified with preliminary tests (data not shown).

More detailed information about the inoculum and the laboratory-scale plant is reported in Tomei and Carozza (2014).

\section{Analysis}

Sample collection of raw, anaerobic and aerobic digested sludge was started 1 week after start-up. Samples were analysed for volatile solids (VS), total solids (TS) ammonia, nitrite and nitrate nitrogen. Biogas production rate and 
Table 1 Nitrification-

denitrification kinetic test plan

\begin{tabular}{lllll}
\hline Test & VS $(\mathrm{g} / \mathrm{L})$ & $\mathrm{VS} / \mathrm{TS}$ & $\mathrm{N}^{-\mathrm{NH}_{4}}(\mathrm{mgN} / \mathrm{L})$ & Process \\
\hline N1 & 10.8 & 0.60 & 301 & Nitrification \\
N2 & 15.5 & 0.59 & 182 & Nitrification \\
ND3 & 13.3 & 0.62 & 103 & Nitrification/denitrification \\
ND4 & 9.4 & 0.56 & 133 & Nitrification/denitrification \\
ND5 & 13.5 & 0.60 & 174 & Nitrification/denitrification \\
\hline
\end{tabular}

$\mathrm{N}-\mathrm{NH}_{4}$ values are the initial concentration in the tests methane fraction were also measured. Analytical methods and devices are listed in the following.

\section{Volatile and total solids}

VS and TS concentrations were measured according to the Standard Methods (APHA 1998).

\section{Nitrogen}

Ammonia, nitrites and nitrates were determined according to the Standard Methods (APHA 1998). All experimental data and mass balance calculations for ammonium nitrogen, nitrites and nitrates are expressed in terms of nitrogen.

\section{Methane}

Methane in the biogas was determined by a gas chromatograph PerkinElmer AutoSystem equipped with a Carboxen 1000 (Supelco) column and a TCD.

\section{Biogas detection device}

The flow rate of biogas produced by the anaerobic reactor was measured by a volumetric counter using a closed water displacement system with electrical contacts and with an electromagnetic valve to discharge the produced biogas to the atmosphere (Mata-Alvarez et al. 1986). A programmable logic controller (PLC) controlled the measurement device and provided the recording of signals.

\section{Kinetic tests}

Aerobic biomass was kinetically characterized for nitrification and denitrification with batch kinetic tests performed in $0.5-\mathrm{L}$ flasks (work volume $0.4 \mathrm{~L}$ ). Temperature was controlled at $T=20 \pm 0.5^{\circ} \mathrm{C}$ by a thermostatic bath. The sludge taken from the aerobic reactor was opportunely diluted to achieve an initial $\mathrm{N}-\mathrm{NH}_{4}$ concentration in the range of $100-300 \mathrm{mg} \mathrm{N} / \mathrm{L}$; VS and TS were measured at the beginning of the test.
DO was controlled in the range of $3-4 \mathrm{mg} / \mathrm{L}$. In nitrification tests, the sludge was mixed with a magnetic stirrer and aerated for $24 \mathrm{~h}$. In nitrification/denitrification tests, after the aerobic stage, the aeration was stopped and the sludge was kept for $24 \mathrm{~h}$ under anoxic conditions. Nitrogen species $\mathrm{N}-\mathrm{NH}_{4}, \mathrm{~N}-\mathrm{NO}_{2}$ and $\mathrm{N}-\mathrm{NO}_{3}$ were measured at regular time intervals.

In Table 1, an overview of the test plan is reported.

\section{Modelling}

\section{Nitrification}

It has been assumed the classical nitrification two-step process the first converting ammonia to nitrites catalysed by Nitrosomonas and the second nitrites to nitrates performed by Nitrobacters. The mass balance equations in a batch system for the three nitrogen species $\mathrm{N}-\mathrm{NH}_{4}, \mathrm{~N}-\mathrm{NO}_{2}$, $\mathrm{N}-\mathrm{NO}_{3}$ are expressed by the following equations:

$\frac{\mathrm{dN}-\mathrm{NH}_{4}}{\mathrm{~d} t}=-\mathrm{k}_{\mathrm{NH} 4} \mathrm{X}_{\mathrm{N}} \frac{\mathrm{N}-\mathrm{NH}_{4}}{\left(\mathrm{~N}-\mathrm{NH}_{4}+\mathrm{Ks}_{\mathrm{NH} 4}\right)}$

$\frac{\mathrm{dN}-\mathrm{NO}_{3}}{\mathrm{~d} t}=\mathrm{k}_{\mathrm{NO} 3} \mathrm{X}_{\mathrm{N}} \frac{\mathrm{N}-\mathrm{NO}_{2}}{\left(\mathrm{~N}-\mathrm{NO}_{2}+\mathrm{Ks}_{\mathrm{NO} 2}\right)}$

$$
\begin{aligned}
\frac{\mathrm{dN}-\mathrm{NO}_{2}}{\mathrm{~d} t}= & \mathrm{k}_{\mathrm{NH} 4} \mathrm{X}_{\mathrm{N}} \frac{\mathrm{N}-\mathrm{NH}_{4}}{\left(\mathrm{~N}-\mathrm{NH}_{4}+\mathrm{Ks}_{\mathrm{NH} 4}\right)} \\
& -\mathrm{k}_{\mathrm{NO} 3} \mathrm{X}_{\mathrm{N}} \frac{\mathrm{N}-\mathrm{NO}_{2}}{\left(\mathrm{~N}-\mathrm{NO}_{2}+\mathrm{Ks}_{\mathrm{NO} 2}\right)}
\end{aligned}
$$

where $\mathrm{N}-\mathrm{NH}_{4}$ is the ammonia nitrogen concentration, $\mathrm{N}-\mathrm{NO}_{2}$ the nitrite nitrogen concentration, $\mathrm{N}-\mathrm{NO}_{3}$ the nitrate nitrogen concentration, $\mathrm{k}_{\mathrm{NH} 4}$ the maximum ammonia removal rate, $\mathrm{k}_{\mathrm{NO} 3}$ the maximum nitrate formation rate, $\mathrm{Ks}_{\mathrm{NH} 4}$ the saturation constant for the first nitrification step and $\mathrm{Ks}_{\mathrm{NO} 2}$ the saturation constant for the second nitrification step and $\mathrm{X}_{\mathrm{N}}$ the nitrifying biomass concentration.

According to the IWA task group on modelling (Henze et al. 1987; Akhbari et al. 2012), a Michaelis-Menten-like kinetics was assumed and the limiting effect of dissolved oxygen has not been included in the kinetic equations being the oxygen furniture ensured in excess during the aerobic batch tests. 
It is worth noting that as it is common practice for biological processes, proposed models are based on "lumped" (or apparent) parameters, that is, parameters accounting (besides the kinetics) different phenomena such as mass transfer resistances for substrates and oxygen, and inhibition phenomena. In this specific case, for example, a possible inhibition effect could be exerted by free ammonia. The "lumped" parameters take into account the effect of the other parameters with consequent simplification in model formulation, but they have to be evaluated through model calibration and verified by the validation step.

\section{Denitrification}

In modelling of denitrification process, the kinetic equation was modified with a "switching function" depending on the oxygen concentration to properly take into account that the process is occurring in conditions of intermittent aeration. This is why if oxygen is present in the system, it will be preferentially utilized as electron acceptor instead of nitrate. The concept of switching function in modelling biological processes was firstly introduced by the task group of the International Association on Water Pollution Research Control (IAWPRC), in their Activated Sludge Model No. 1 (Henze et al. 1987) to gradually turn process rate equations on and off as the environmental conditions were changed. The switching functions are "Monod-like" expressions that are mathematically continuous and thereby reduce the problems of numerical instability during simulations. It results the following kinetic equation for denitrification:

$\frac{\mathrm{dN}-\mathrm{NO}_{3}}{\mathrm{~d} t}=-\mathrm{k}_{\mathrm{D}} \mathrm{X}_{\mathrm{D}} \frac{\mathrm{N}-\mathrm{NO}_{3}}{\left(\mathrm{~N}-\mathrm{NO}_{3}+\mathrm{Ks}_{\mathrm{NO} 3}\right)} \frac{\mathrm{K}_{\mathrm{O} 2}}{\left(\mathrm{~K}_{\mathrm{O} 2}+\mathrm{DO}\right)}$

where DO is the concentration of the dissolved oxygen, $\mathrm{k}_{\mathrm{D}}$ the maximum nitrate removal rate, $X_{D}$ the denitrifying biomass concentration and $\mathrm{Ks}_{\mathrm{NO} 3}$ the saturation constant for the denitrification step. $\mathrm{K}_{\mathrm{O} 2}$ represents the inhibition constant accounting for the reduction on the denitrification kinetics due to the presence of residual oxygen from the aerobic phase: the higher is the $\mathrm{K}_{\mathrm{O} 2}$ value, the lowest the inhibitory effect, that is, not significant when $\mathrm{DO} \ll \mathrm{K}_{\mathrm{O} 2}$.

\section{Results and discussion}

\section{Sequential digestion process performance}

A summary of the characterization data for influent sludge and digestates is shown in Table 2 as mean value \pm standard deviation (SD) of the data referring to the entire experimental period.

Even if the paper is focused on the nitrogen fate in the sequential sludge stabilization, COD and VS characterization data, for the in and out streams, are given to illustrate the general process potentialities and the operating conditions of the reaction environment where the biomass was developed. In the following paragraph, a summary of the process performance in terms of "classical" digestion performance parameters (VS removal and biogas production) is also presented to complete the picture of information. A detailed analysis of the process performance is reported elsewhere (Tomei and Carozza 2014).

\section{Solid removal and biogas production}

Experimental data in Fig. 1a, b, averaged on two-week periods, show the effective VS reduction in the sequential process: $47.1 \pm 5.5 \%$ in the anaerobic digester plus $26.3 \pm 5.3 \%$ in the post-aerobic stage, giving an overall VS removal of $61 \%$. Figure 1a also shows the organic loading rates (OLRs) of the two stages: it is worth noting that an increase in the anaerobic OLR has a positive effect on VS removal in both stages. As shown in Fig. 1a, when the OLR drops below $1.2 \mathrm{~kg} \mathrm{VS} / \mathrm{m}^{3}$ day, the VS removal efficiency in the anaerobic reactor decreases to $\sim 40 \%$. Moreover, for the aerobic process, in the first operation period with an OLR of $0.8 \pm 0.3 \mathrm{~kg} \mathrm{VS} / \mathrm{m}^{3}$ day, the VS removal of the aerobic phase remained below $20 \%$, while
Table 2 Characterization data for VS, COD and nitrogen species in influent and effluent of the anaerobic and aerobic reactor

\begin{tabular}{cc|c|c|c}
\hline \multirow{2}{*}{ Parameter } & \multicolumn{2}{c}{ ANAEROBIC REACTOR } & \multicolumn{2}{c}{ AEROBIC REACTOR } \\
\cline { 2 - 4 } & $\mathrm{IN}$ & OUT & IN & OUT \\
\hline & $145 \pm 41$ & $451 \pm 90$ & $169 \pm 26$ \\
$\mathrm{COD}_{\text {sol }}(\mathrm{mg} / \mathrm{L})$ & $38.2 \pm 5.2$ & $20.7 \pm 2.1$ & $14.9 \pm 1.3$ \\
$\mathrm{COD}_{\text {tot }}(\mathrm{g} / \mathrm{L})$ & $10.3 \pm 3$ & $838.8 \pm 62.7$ & $191.6 \pm 82.4$ \\
$\mathrm{~N}-\mathrm{NH}_{4}(\mathrm{mg} / \mathrm{L})$ & $1.9 \pm 0.8$ & $35.3 \pm 17.6$ & $208.4 \pm 87.3$ \\
$\mathrm{~N}-\mathrm{NO}_{2}(\mathrm{mg} / \mathrm{L})$ & $10.6 \pm 2.9$ & $29.2 \pm 8.6$ & $269.7 \pm 65.1$ \\
$\mathrm{~N}-\mathrm{NO}_{3}(\mathrm{mg} / \mathrm{L})$ & $2.57 \pm 0.35$ & $1.37 \pm 0.14$ & $1.01 \pm 0.09$ \\
$\mathrm{VS}(\%)$ & & &
\end{tabular}



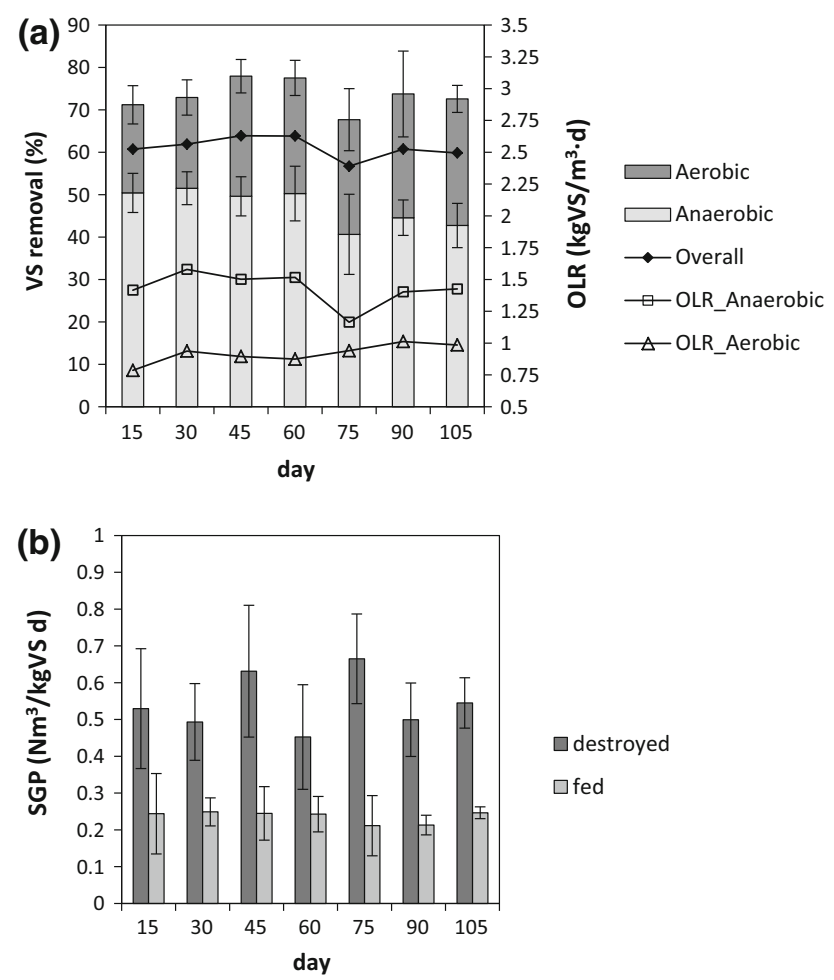

Fig. 1 OLRs and VS removal efficiencies in the two-stage anaerobic-aerobic process (a) and specific biogas production referred to the unit of destroyed and fed VS (b)

the OLR increase to 1.1 resulted in an increase in the VS removal efficiency up to $29 \%$.

The specific biogas production (SGP), referring to both destroyed and fed VS, is shown in Fig. 1b: the average SGP is $0.54 \pm 0.07$ and $0.24 \pm 0.02 \mathrm{Nm}^{3}$ per $\mathrm{kg}$ of VS destroyed and added, respectively. Both values are in agreement with the range of values reported in the specialized literature for WAS (Bolzonella et al. 2005). Furthermore, the gas production rate (GPR) was $0.41 \pm 0.1 \mathrm{~m}_{\text {biogas }}^{3} / \mathrm{m}_{\text {reactor }}^{3}$ day, higher than literature values 0.04-0.18 reported by Bolzonella et al. (2005). The methane content of the produced biogas has been periodically measured, and the detected methane fraction is $66 \%$.

\section{Nitrogen removal}

Simultaneous nitrification-denitrification has been achieved in the aerobic stage due to the on/off aeration strategy: Fig. 2 shows a typical DO pattern of an intermittent aeration cycle. During the aeration, DO concentration was maintained above $3 \mathrm{mg} / \mathrm{L}$, as suggested by Zupancic and Ros (2008) as the minimum value required having nitrification in a concentrated sludge suspension where mass transfer resistances are significantly higher if compared with the mixed liquor of the WWTP aeration tank.

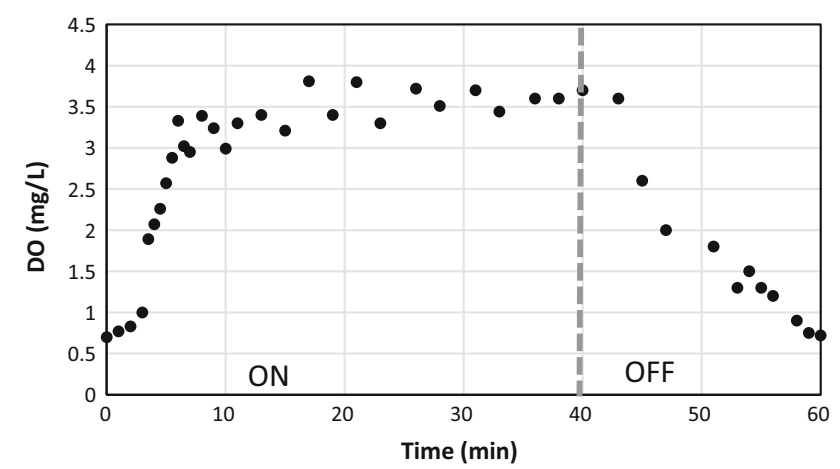

Fig. 2 Typical DO time profile detected in aerobic-anoxic phases in the bioreactor

Figure $3 \mathrm{a}, \mathrm{b}$ shows the nitrogen species pattern in the anaerobic and aerobic digester, respectively, while the progressive trends of nitrification-denitrification efficiencies are reported in Fig. 3c. Nitrification and denitrification efficiencies have been calculated through mass balances referred to ammonia, nitrite and nitrate nitrogen in the supernatant and associated with the VS. The nitrification efficiency given by the following equation

$\begin{aligned} \mathrm{RE}_{\mathrm{NIT}}= & \frac{\left(\mathrm{N}-\mathrm{NH}_{4 \text { fed }}+\mathrm{N}-\mathrm{NH}_{4 \text { hyd }}-\mathrm{N}-\mathrm{NH}_{4 \mathrm{eff}}\right)}{\left(\mathrm{N}-\mathrm{NH}_{4 \mathrm{fed}}+\mathrm{N}-\mathrm{NH}_{4 \text { hyd }}\right)} \\ & \times 100\end{aligned}$

has been evaluated as the per cent ratio between the nitrified nitrogen and the ammonia nitrogen available for nitrification, i.e. fed to the aerobic reactor $\left(\mathrm{N}^{\left.-\mathrm{NH}_{4 \mathrm{fed}}\right)}\right.$ and produced in the aerobic hydrolysis of removed VS (N$\mathrm{NH}_{4 \text { hyd }}$ ). This latter nitrogen input according to Angelidaki et al. (1999) and Siegrist et al. (2002) has been determined assuming a stoichiometric coefficient of 1 for VS hydrolysis; therefore, we can approximately assume that the released nitrogen is equal to the nitrogen content associated with the hydrolysed sludge. The fed sludge in this case is the anaerobic digested sludge for which, according to European Commission (EU 2002), the nitrogen content varies within the range of $2.5-14 \%$ of the VS depending on the characteristics of the fed sludge and on the operating conditions of the digestion. In our case, a mean value of $10 \%$ (referred to VS) has been assumed, also confirmed by experimental measurements (data not shown).

The denitrification efficiency was evaluated as follows

$\mathrm{RE}_{\mathrm{DEN}}=\frac{\left(\mathrm{N}-\mathrm{NO}_{\text {xfed }}+\mathrm{N}-\mathrm{NO}_{\text {xnit }}-\mathrm{N}-\mathrm{NO}_{\text {xeff }}\right)}{\left(\mathrm{N}-\mathrm{NO}_{\mathrm{xfed}}+\mathrm{N}-\mathrm{NO}_{\text {xnit }}\right)} \times 100$

as the ratio between the denitrified nitrogen and the $\mathrm{N}-\mathrm{NO}_{\mathrm{x}}$ available for denitrification given by the sum of the $\mathrm{N}^{-\mathrm{NO}_{\mathrm{x}}}$ fed to the reactor $\left(\mathrm{N}-\mathrm{NO}_{\mathrm{xfed}}\right)$ and the $\mathrm{N}-\mathrm{NO}_{\mathrm{x}}$ produced in the nitrification step $\left(\mathrm{N}-\mathrm{NO}_{\text {xnit }}\right)$. 

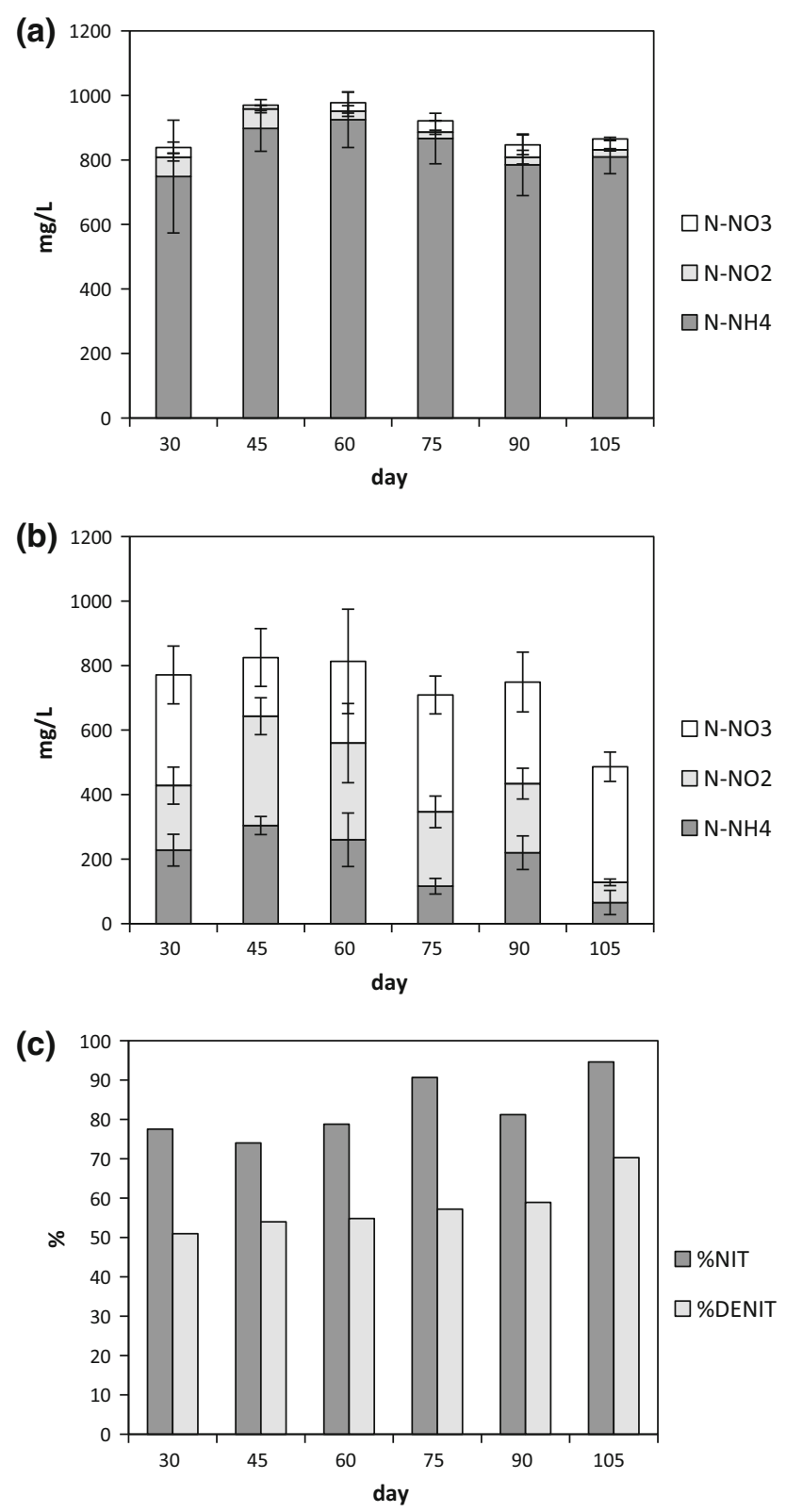

Fig. 3 Nitrogen speciation in anaerobic (a) and aerobic digested (b) sludge, and nitrification and denitrification efficiency (c) during the entire experimental period. Error bars are the standard deviation of daily measurements in the period. Total and ammonia nitrogen concentrations in the feed are $22.8 \pm 5.1$ and $10 \pm 3 \mathrm{mg} / \mathrm{L}$

In order to verify the COD availability for denitrification, the mass balance of COD and nitrogen has been done with reference to the data of Table 2 . The $\mathrm{COD} / \mathrm{N}$ ratio in the feed to the aerobic reactor is $24.7 \pm 2.4$, so high enough to sustain denitrification (Khorsandi et al. 2011), also considering that the range of values of the stoichiometric $\mathrm{COD} / \mathrm{N}$ ratio reported in the specialized literature for the denitrification process is 4-8.6 (Ritman and Langeland 1985; Ekama and Marais 1984; Carrera et al. 2004). The $\mathrm{COD} / \mathrm{N}$ values are depending on the carbon source: the lower value of 4 is for readily biodegradable COD (i.e. acetate), while the upper value is for the endogenous carbon and it is applicable to this study where the soluble COD is significantly lower than the particulate COD associated with WAS.

Gradual improvements in nitrification and denitrification efficiencies have been observed, with values in the range of 77-95 and 51-70\% for nitrification and denitrification, respectively. Observed efficiencies are comparable to the values reported in the specialized literature for the postaerobic digestion of mixed sludge (Novak et al. 2011; Parravicini et al. 2008). Achieved results are significant for the reduction in the nitrogen load recycled to the wastewater treatment plant.

\section{Modelling—nitrogen fate}

Nitrogen fate in the two-stage system has been also investigated through nitrification-denitrification kinetic tests whose data have been analysed to determine the kinetic parameters of the simultaneous nitrification-denitrification process. The evaluation of kinetic parameters for nitrification and denitrification has been performed by a first calibration step consisting in the data fitting of a first data set followed by a validation step to verify the reliability of the determined parameters in predicting data of another series of tests. In the calibration phase, data of N2 and ND3 tests have been correlated with the proposed models for the nitrification and denitrification processes, respectively. Evaluated best-fitting parameters were employed to predict the results of the other tests in the validation phase.

According to experimental VS concentration values, it was assumed that the biomass levels remained practically constant throughout each run. Nitrifying biomass has been assumed $\sim 5 \%$ of the total biomass, while the remaining fraction is constituted by heterotrophic denitrifying biomass. This distribution derives by average data (in the range of 4-6\%) reported for activated sludge (Henze et al. 2000; Choubert et al. 2005). The assumption has been done to facilitate the comparison with literature data, which are generally expressed in terms of nitrifying biomass.

In Fig. 4a, b, referring to nitrification tests, experimental and calculated ammonia, nitrites and nitrates concentration profiles are reported for calibration and validation, respectively. Very good fitting of the experimental data was also observed in the validation step with correlation 

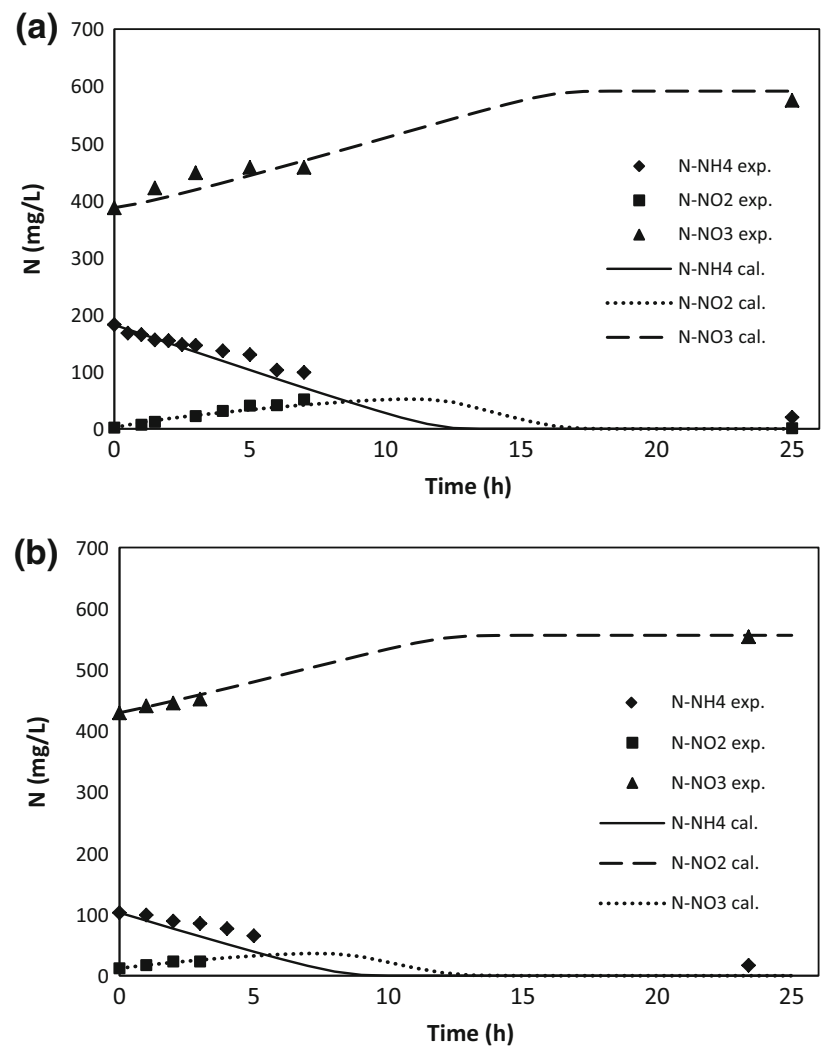

Fig. 4 Nitrogen species experimental and calculated concentration profiles in nitrification test: data fitting for model calibration (test N2) (a) and validation (test ND3) (b)

coefficients $R^{2} \geq 0.98$. Evaluated kinetic parameters are reported in Table 3 for comparison with literature values. $\mathrm{k}_{\mathrm{NH} 4}$ and $\mathrm{k}_{\mathrm{NO} 3}$ values in the table are referred to the estimated values of nitrifying biomass, and corresponding values referred to the total VS (i.e. the total biomass) are 0.028 and 0.023 , respectively.

Figure 5 shows a typical nitrate profile detected in a nitrification-denitrification test. For denitrification, it is observed that after a slow initial decrease due to the residual oxygen from the previous aerobic stage, the removal rate increases. This pattern is expected in conditions of intermittent aeration and highlights the needs of considering the oxygen limiting effect in modelling the process kinetics.

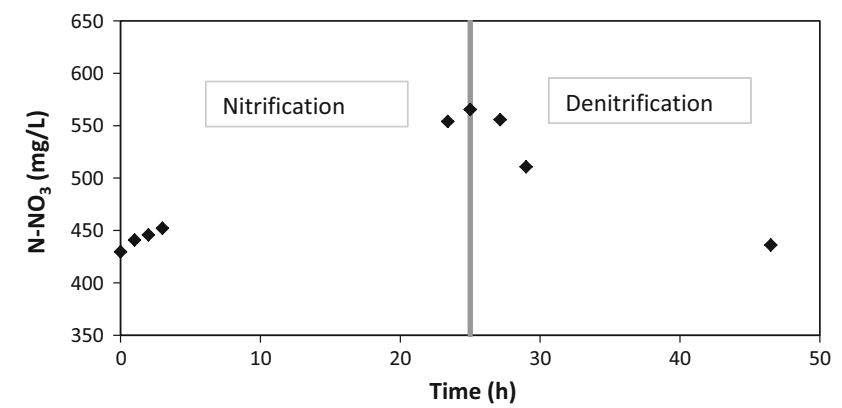

Fig. 5 Typical experimental nitrate concentration profile in a nitrification-denitrification test
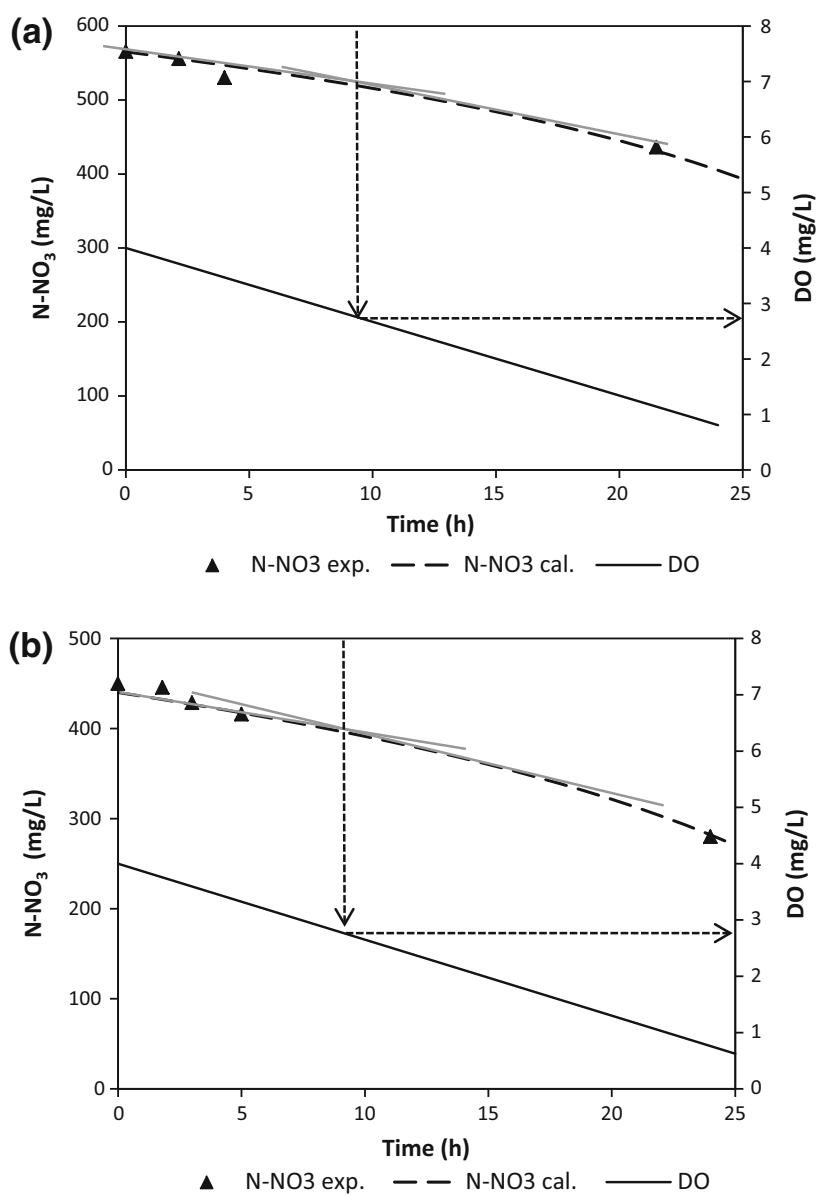

Fig. 6 Experimental and calculated nitrate concentration profile in nitrification-denitrification tests: calibration (ND3 test) (a) and validation (ND4 test) (b). Calculated DO concentration profile

Table 3 Kinetic parameters for nitrification process

\begin{tabular}{lllll}
\hline Parameter & Units & Value determined in this study & Literature values & Reference \\
\hline $\mathrm{k}_{\mathrm{NH} 4}$ & $\mathrm{mg} \mathrm{N} / \mathrm{mg}$ VSS day & 0.56 & $1.2-3.5$ & Stensel and Barnard (1992) \\
$\mathrm{Ks}_{\mathrm{NH} 4}$ & $\mathrm{mg} \mathrm{N} / \mathrm{L}$ & 5.12 & $0.06-5.6$ & Sharma and Ahlert (1977) \\
$\mathrm{k}_{\mathrm{NO} 3}$ & $\mathrm{mg} \mathrm{N} / \mathrm{mg}$ VSS day & 0.46 & - & - \\
$\mathrm{Ks}_{\mathrm{NO} 2}$ & $\mathrm{mg} \mathrm{N} / \mathrm{L}$ & 4.70 & - & - \\
\hline
\end{tabular}


Table 4 Kinetic parameters for denitrification process

\begin{tabular}{llcll}
\hline Parameter & Units & Value determined in this study & Literature values & Reference \\
\hline $\mathrm{k}_{\mathrm{D}}$ & $\mathrm{mg} \mathrm{N} / \mathrm{mg}$ VSS day & 0.043 & $0.05-4.8$ & Henze et al. (1994) \\
$\mathrm{Ks}_{\mathrm{NO} 3}$ & $\mathrm{mg} \mathrm{N} / \mathrm{L}$ & 60 & $0.5-9.1$ & Henze et al. (2000) and Stensel and Barnard (1992) \\
$\mathrm{K}_{\mathrm{O} 2}$ & $\mathrm{mg} \mathrm{O}_{2} / \mathrm{L}$ & 1 & 0.1 & Henze et al. (1987) \\
\hline
\end{tabular}

Literature values are for activated sludge systems treating urban wastewater

In Fig. 6a, b, experimental and calculated nitrate and DO profiles in denitrification tests are reported for model calibration and validation, respectively. Also in this case a very good correlation is observed with correlation coefficients $R^{2} \geq 0.98$. In addition, the reported DO profile was calculated from the oxygen mass balance by assuming, according to Tomei et al. (2011b), a first-order VS removal kinetics with a decay rate of $0.25 \mathrm{day}^{-1}$. The comparison between nitrate and dissolved oxygen profiles effectively highlights the DO effect on denitrification kinetics. The nitrate concentration pattern exhibits the classical double slope concentration profile typical of substrate-inhibited kinetics (as highlighted by tangent lines reported in Fig. 6). We observed a change in the slope in correspondence of a DO concentration value of about $3 \mathrm{mg} / \mathrm{L}$ (showed by the arrows in the two above-mentioned figures), confirming the DO limiting value reported in Zupancic and Ros (2008).

In Tables 3 and 4, calculated nitrification and denitrification kinetic parameters are shown in comparison with literature values for conventional activated sludge process. The maximum nitrification rate is lower than the literature value, but this may be consistent with the higher mass transfer resistances characterizing the reaction environment in the digester in comparison with the conventional activated sludge aeration tank: this suggest that higher DO concentration could give a better nitrification performance. On the other side, too high DO values cause a delay in achieving satisfactory denitrification rates in the following anoxic phase as well that highlighted in Fig. 6a, b. These results show that the DO level is a critical operating parameter to optimize in order to achieve efficient nitrogen removal, as also reported in Guo et al. (2008).

Maximum denitrification rate is comparable with the literature value $\left(0.05 \mathrm{day}^{-1}\right)$ reported by Henze et al. (1994) when an endogenous carbon source is used (as in this case). Other parameters for both nitrification and denitrification are comparable with the literature values except $\mathrm{K}_{\mathrm{O} 2}$ whose higher value (i.e. lower inhibitory oxygen effect) could be explained by the partial penetration of oxygen inside the bioflocs again attributable to higher diffusion resistances in the sludge digester operated at higher VS concentration in comparison with activated sludge bioreactors.

\section{Conclusion}

Sequential anaerobic-aerobic digestion of WAS was demonstrated to be effective in achieving good performance of the nitrification-denitrification process when the aerobic stage is operated with intermittent aeration. A detailed kinetic study of nitrification and denitrification (including all the nitrogen species) has been performed, for the post-aerobic digestion. Average nitrification and denitrification efficiencies were 95 and $70 \%$, respectively, and consequent nitrogen removal efficiencies (up to $62 \%$ ) significantly reduce the nitrogen load recycled to the plant.

The proposed model for nitrogen removal in the postaerobic stage was calibrated and successfully validated with the experimental data of the batch tests. The evaluated parameters showed very good predictions in the validation phase with correlation coefficient always $>0.98$; thus, the applied modelling approach is suitable to predict the fate of the nitrogen species in the sequential digestion. We operated with real waste sludge, so the model and the related parameters are of general validity in that they can be considered representative of real wastewater treatment plant operation.

Acknowledgments This work was supported by the EU ROUTES project funded from the European Union's Seventh Programme for research, technological development and demonstration under Grant Agreement No. 265156.

\section{Nomenclature}

DO Dissolved oxygen $\left(\mathrm{mg} \mathrm{O}_{2} / \mathrm{L}\right)$

$\mathrm{k}_{\mathrm{NH} 4} \quad$ Maximum ammonia removal rate $(\mathrm{mg} \mathrm{N}-$ $\mathrm{NH}_{4} / \mathrm{mg}$ VS day)

$\mathrm{Ks}_{\mathrm{NH} 4} \quad$ Saturation constant for the first nitrification step (mg N-NH$/ /$ L)

$\mathrm{k}_{\mathrm{NO} 3}$ Maximum nitrate formation rate (mg N$\mathrm{NO}_{3} / \mathrm{mg}$ VS day)

$\mathrm{Ks}_{\mathrm{NO} 2}$ Saturation constant for the second nitrification step $\left(\mathrm{mg} \mathrm{N}-\mathrm{NO}_{2} / \mathrm{L}\right)$

$\mathrm{k}_{\mathrm{D}} \quad$ Maximum nitrate removal rate $\left(\mathrm{mg} \mathrm{N}-\mathrm{NO}_{3} /\right.$ mg VS day) 


\begin{tabular}{|c|c|}
\hline $\mathrm{K}_{\mathrm{O} 2}$ & Oxygen inhibition constant $\left(\mathrm{mg}_{2} / \mathrm{L}\right)$ \\
\hline $\mathrm{Ks}_{\mathrm{NO} 3}$ & $\begin{array}{l}\text { Saturation constant for denitrification } \\
\left(\mathrm{mg} \mathrm{N}-\mathrm{NO}_{3} / \mathrm{L}\right)\end{array}$ \\
\hline $\mathrm{N}-\mathrm{NH}_{4}$ & Ammonia nitrogen concentration $(\mathrm{mg} \mathrm{N} / \mathrm{L})$ \\
\hline $\mathrm{N}-\mathrm{NH}_{4}$ eff & Ammonia nitrogen in the effluent ( $\mathrm{mg} \mathrm{N} / \mathrm{L}$ ) \\
\hline $\mathrm{N}-\mathrm{NH}_{4 \mathrm{fed}}$ & Ammonia nitrogen in the influent $(\mathrm{mg} \mathrm{N} / \mathrm{L})$ \\
\hline $\mathrm{N}-\mathrm{NH}_{4 \text { hyd }}$ & $\begin{array}{l}\text { Ammonia nitrogen produced from VS } \\
\text { hydrolysis }(\mathrm{mg} \mathrm{N} / \mathrm{L})\end{array}$ \\
\hline $\mathrm{N}-\mathrm{NO}_{2}$ & Nitrite nitrogen concentration (mg N/L) \\
\hline $\mathrm{N}-\mathrm{NO}_{3}$ & Nitrate nitrogen concentration (mg N/L) \\
\hline $\mathrm{N}-\mathrm{NO}_{\text {xeff }}$ & $\begin{array}{l}\text { Nitrite and nitrate nitrogen in the effluent } \\
(\mathrm{mg} \mathrm{N} / \mathrm{L})\end{array}$ \\
\hline $\mathrm{N}-\mathrm{NO}_{\text {xfed }}$ & $\begin{array}{l}\text { Nitrite and nitrate nitrogen in the influent } \\
(\mathrm{mg} \mathrm{N} / \mathrm{L})\end{array}$ \\
\hline $\mathrm{N}-\mathrm{NO}_{\text {xnit }}$ & $\begin{array}{l}\text { Nitrite and nitrate nitrogen produced in } \\
\text { nitrification }(\mathrm{mg} \mathrm{N} / \mathrm{L})\end{array}$ \\
\hline $\mathrm{RE}_{\mathrm{DEN}}$ & Per cent removal efficiency in denitrification \\
\hline $\mathrm{RE}_{\mathrm{NIT}}$ & Per cent removal efficiency in nitrification \\
\hline TS & Total solids $(\mathrm{mg} / \mathrm{L})$ \\
\hline VS & Volatile solids (mg/L) \\
\hline $\mathrm{X}_{\mathrm{N}}$ & Nitrifying biomass concentration (mg VS/L) \\
\hline $\mathrm{X}_{\mathrm{D}}$ & $\begin{array}{l}\text { Denitrifying biomass } \\
(\mathrm{mg} \mathrm{VS} / \mathrm{L})\end{array}$ \\
\hline & Waste activated sludge \\
\hline & Wastewater treatment plant \\
\hline
\end{tabular}

\section{References}

Akhbari A, Zinatizadeh AAL, Mohammadi P, Mansouri Y, Irandoust M, Isa MH (2012) Kinetic modeling of carbon and nutrients removal in an integrated rotating biological contactor-activated sludge system. Int J Environ Sci Technol 9(2):371-378

Angelidaki I, Ellegaard L, Ahring BK (1999) A comprehensive model of anaerobic bioconversion of complex substrates to biogas. Biotechnol Bioeng 63(3):363-372

APHA (1998) Standard methods for the examination of water and wastewater, 20th edn. APHA, Washington

Bolzonella D, Pavan P, Battistoni P, Cecchi F (2005) Mesophilic anaerobic digestion of waste activated sludge: influence of the solid retention time in the wastewater treatment process. Process Biochem 40:1453-1460

Carrera J, Vicent T, Lafuente J (2004) Effect of influent COD/N ratio on biological nitrogen removal (BNR) from high-strength ammonium industrial wastewater. Process Biochem 39:2035-2041

Choubert JM, Racault Y, Grasmick A, Beck C, Heduit A (2005) Nitrogen removal from urban wastewater by activated sludge process operated over the conventional carbon loading rate limit at low temperature. Water SA 31:503-510

Ekama GA, Marais GVR (1984) Theory, design and operation of nutrient removal activated sludge processes. Water Res Comm, Pretoria, South Africa 4-1:4-20
European Commission (EU) DG Environment B/2 (2002) Disposal and recycling routes for sewage sludge EU. Part 3-scientific and technical report, Luxembourg, pp 72. http://ec.europa.eu/ environment/archives/waste/sludge/pdf/sludge_disposal3.pdf. Accessed July 2015

Guo X, Kim JH, Behera SK, Park HS (2008) Influence of dissolved oxygen concentration and aeration time on nitrite accumulation in partial nitrification process. Int $\mathbf{J}$ Environ Sci Technol 5(4):527-534

Henze M, Grady Jr CPL, Gujer W, Marais GVR, Matsuo T (1987) Activated Sludge Model No. 1. IAWPRC scientific and technical reports no. 1, IAWPRC. IWA Publishing, London, pp 38

Henze M, Kristensen GH, Strube R (1994) Rate-capacity characterization of wastewater for nutrient removal processes. Water Sci Technol 29(7):101-107

Henze M, Gujer W, Mino T, van Loosdrecht M (2000) Activated Sludge Models ASM1, ASM2, ASM2D, ASM3. IAWPRC scientific and technical reports no. 9, IAWPRC. IWA Publishing, London, pp 121

Kelessidis A, Stasinakis AS (2012) Comparative study of the methods used for treatment and final disposal of sewage sludge in European countries. Waste Manag 32:1186-1195

Khorsandi H, Movahedyan H, Bina B, Farrokhzadeh H (2011) Innovative anaerobic upflow sludge blanket filtration combined bioreactor for nitrogen removal from municipal wastewater. Int J Environ Sci Technol 8(2):417-424

Kumar N, Novak JT, Murthy S (2006) Effect of secondary aerobic digestion on properties of anaerobic digested biosolids. In: Water Environmental Federation 79th annual technical exhibition and conference, Dallas, pp 6806-6829

Mata-Alvarez J, Mtz-Viturtia A, Torres R (1986) A simple device to measure biogas production in laboratory scale digesters. Biotechnol Lett 8:719-720

Mininni G, Braguglia CM, Ramadori R, Tomei MC (2004) An innovative sludge management system based on separation of primary and secondary sludge treatment. Water Sci Technol 50:145-153

Novak JT, Banjade S, Murthy SN (2011) Combined anaerobicaerobic digestion for increased solids reduction and nitrogen removal. Water Res 45:618-624

Parravicini V, Svardal K, Hornek R, Kroiss H (2008) Aeration of anaerobically digested sewage sludge for COD and nitrogen removal: optimization at large-scale. Water Sci Technol 57:257-264

Ritman BE, Langeland WE (1985) Simultaneous denitrification in single channel oxidation ditches. J Wat Pollut Control Fed 57:300-307

Sharma B, Ahlert RC (1977) Nitrification and nitrogen removal. Water Res 11:897-925

Siegrist H, Vogt D, Garcia-Heras J, Gujer W (2002) Mathematical model for meso and thermophilic anaerobic sewage sludge digestion. Environ Sci Technol 36:1113-1123

Stensel H, Barnard J (1992) Principles of biological nutrient removal. In: Randall C, Barnard J, Stensel H (eds) Design and retrofit of wastewater treatment plants for biological nutrient removal. Technomic Publishing, Lancaster

Tomei MC, Carozza NA (2014) Sequential anaerobic/anaerobic digestion for enhanced sludge stabilization: comparison of the process performance for mixed and waste sludge. Environ Sci Pollut Res. doi:10.1007/s11356-014-3130-2

Tomei MC, Rita S, Mininni G (2011a) Performance of sequential anaerobic/aerobic digestion applied to municipal sewage sludge. J Environ Manage 92:1867-1873 
Tomei MC, Rita S, Mininni G (2011b) Sequential anaerobic/aerobic digestion of waste activated sludge: analysis of the process performance and kinetic study. New Biotechnol 29:17-22
Zupancic GD, Ros M (2008) Aerobic and two-stage anaerobicaerobic sludge digestion with pure oxygen and air aeration. Bioresour Technol 99:100-109 